\title{
Comparison of Laparoendoscopic Single-Site Radical Nephrectomy with Conventional Laparoscopic Radical Nephrectomy for Localized Renal-Cell Carcinoma
}

\author{
Yong Hyun Park, M.D., Ji Hyun Park, M.D., Chang Wook Jeong, M.D., and Hyeon Hoe Kim, M.D., Ph.D.
}

\begin{abstract}
Purpose: To compare the results of laparoendoscopic single-site (LESS) radical nephrectomy with conventional laparoscopic radical nephrectomy for localized renal-cell carcinoma (RCC).

Patients and Methods: This study was designed as a matched case-controlled study from our institute's RCC database. Nineteen consecutive patients who were undergoing LESS radical nephrectomy were compared with 38 patients who were undergoing conventional laparoscopic radical nephrectomy. The matching process accounted for sex, age, operative side, and tumor size.

Results: No significant differences were observed in mean operative time (190.8 vs $172.4 \mathrm{~min}, P=0.249$ ), estimated blood loss (143.2 vs $199.5 \mathrm{~mL}, P=0.235)$, and complication rate $(15.8 \%$ vs $21.1 \%, P=0.635)$ between the LESS and conventional laparoscopy groups. Postoperative hospital stay after LESS radical nephrectomy was 2.7 (2-4) days, compared with $3.9(3-7)$ days in the conventional laparoscopy group $(P<0.001)$. Postoperative pain, as measured by visual analog scale at postoperative day 1 (4.7 vs 5.8 points, $P=0.001$ ), 2 (3.4 vs 4.6 points, $P<0.001)$, and 3 (2.7 vs 4.0 points, $P=0.008$ ) was significantly lower in the LESS group.

Conclusion: LESS radical nephrectomy is a feasible and safe surgical option for localized RCC that demonstrates improved cosmetic outcomes and the additional benefits of decreased postoperative pain and decreased hospital stay.
\end{abstract}

\section{Introduction}

S URGICAL RESECTION is the potential curative treatment available for renal-cell carcinoma (RCC). Since the first laparoscopic radical nephrectomy by Clayman and associates $^{1}$ in 1991, laparoscopic radical nephrectomy has been well accepted for localized RCC with oncologic equivalency to open surgery, as well as the known benefit of a minimally invasive approach, including decreased postoperative pain, postoperative hospital stay, blood loss, and perioperative complications. ${ }^{2-5}$

In recent years, attempts have been made to minimize invasiveness by reducing the number of trocars. Natural orifice translumenal endoscopic surgery (NOTES) may represent the final frontier of minimally invasive surgery. ${ }^{6}$ NOTES, however, is more technically challenging, still experimental, and has increased risk for perioperative complications, including bowel perforation and peritonitis. Thus, interest has increased in LESS, which has been reported in variable urologic disease. $^{7}$

Although several investigators have reported their experience with LESS, ${ }^{8-10}$ whether it is equivalent to or better than conventional laparoscopic surgery in terms of overall patient outcome is still a critical question. To clarify that question, we conducted a matched case-control study to compare the results of LESS and conventional laparoscopic radical nephrectomy for localized RCC.

\section{Patients and Methods}

\section{Patient selection and outcome measurement}

We performed 124 conventional laparoscopic radical nephrectomies from August 2000 to February 2009 and 19 LESS radical nephrectomies from March 2009 to September 2009. Clinical tumor stage was based on abdominal CT according to the 1997 Tumor-Node-Metastasis staging system. None of these patients was considered suitable for partial nephrectomy.

The first aim of this study was to evaluate feasibility and safety of LESS radical nephrectomy for localized RCC. Thus, study parameters, including rate of conversion to conventional laparoscopic or open surgery, operative time, estimated blood loss, degree of postoperative pain, postoperative

Department of Urology, Seoul National University College of Medicine, Seoul, Korea. 
hospital stay, and postoperative complications, were collected and entered into a computerized database. The degree of postoperative pain was assessed using a visual analog pain scale at postoperative days 1,2 , and 3 . A visual analog pain scale, with scores ranging from 1 to 10 points, was constructed so that each patient could mark a point along the scale that best represented his or her pain at that time.

The second aim of the study was to compare results that were obtained with LESS radical nephrectomy with those that were obtained with conventional laparoscopic radical nephrectomy. For this purpose, data from the 19 patients who underwent LESS radical nephrectomy were compared retrospectively with data from 38 matched patients who underwent conventional laparoscopic radical nephrectomy. Matching was performed taking into account sex, age, operative side, and tumor size.

After approval by the Institutional Review Board at Seoul National University Hospital, clinical and pathologic data from eligible patients were retrieved from the medical records and reviewed retrospectively.

\section{Operative technique for conventional laparoscopic radical nephrectomy}

Both procedures were performed with the patient in the flank position with the affected side elevated to 70 degrees. We used the transperitoneal approach with the previously described four-port technique. ${ }^{11}$ A 12-mm trocar was inserted along the midclavicular line at the umbilicus level for the laparoscope. The main 12-mm trocar for the operator was inserted along the midclavicular line at the subcostal level. Additional two 5-mm trocars were inserted along the anterior

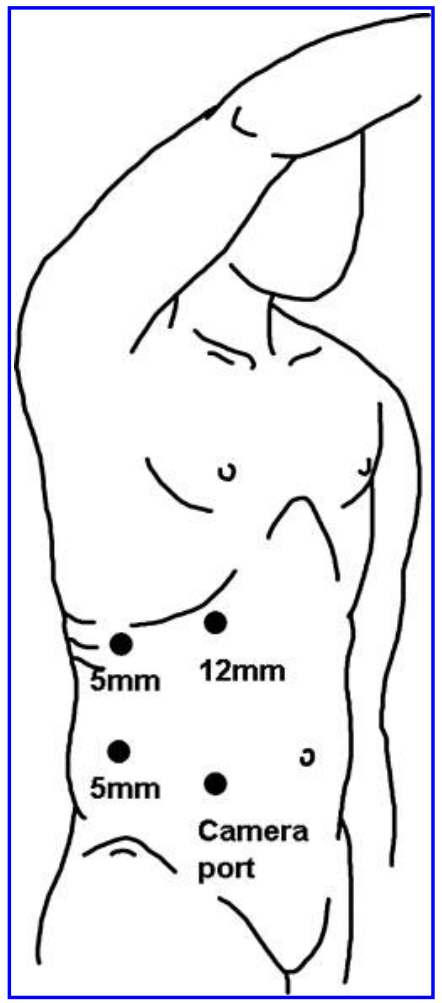

FIG. 1. Trocar placement for conventional laparoscopic radical nephrectomy. axillary line-one at the subcostal level and another at the umbilicus level (Fig. 1). The line of Toldt was incised and the colon was reflected medially.

Dissection then proceeded medially until the hilum was exposed; the renal vein was then isolated and mobilized for access to the artery. The renal artery was first ligated with titanium clips, and, finally, the renal vein was transected using Hem-o-lok clips or staplers. After mobilization of the kidney, the ureter that was isolated during the procedure was clipped and cut. The kidney was placed inside the laparoscopic bag and retrieved through the 50 to $60 \mathrm{~mm}$ muscle splitting incision in the $12-\mathrm{mm}$ port site without morcellation.


FIG. 2. Multichannel single-port device: (A) Homemade single-port device; (B) Octoport ${ }^{\mathrm{TM}}$ system. 


\section{Operative technique for LESS radical nephrectomy}

Regarding LESS radical nephrectomy, a vertical incision, 4 or $4.5 \mathrm{~cm}$ long, was made around the umbilicus. The homemade single-port device, or Octoport ${ }^{\mathrm{TM}}$ (DalimSurgnet, Seoul, Korea) was then inserted at the umbilicus through the incision (Fig. 2). The homemade single-port device was constructed with the previously described technique. ${ }^{12}$ The Octoport is a multi-instrument access port that allows the simultaneous use of up to three or four laparoscopic instruments through separate channels. It consists of an inferior base plate that sits under the skin edge in the peritoneum, an external disc with self-retractor, and transparent silicone cover with three or four channels. Placement of the device is simple and quick (Fig. 3). After insertion of the port and insufflation of the abdomen with $\mathrm{CO}_{2}$, a 5-mm flexible laparoscope with an incorporated light source within the camera head that does not compete for limited space (EndoEye, Olympus, Orangeburg, NY) was introduced.

Using the roticulating laparoscopic instrument (Covidien, Norwalk, CT) to create the necessary angle, along with hook cautery, and ultrasonic scissors, which were part of the standard rigid laparoscopic instrumentation set, LESS radical nephrectomy was performed using procedures similar to those of conventional laparoscopic radical nephrectomy, with no additional extraumbilical incisions. The specimen was placed in the laparoscopic bag and retrieved through the abdominal incision without morcellation (Fig. 4). The incision was closed with a subcuticular absorbable suture (Fig. 4).

\section{Statistical analysis}

We compared surgical outcomes, including operative time, estimated blood loss, degree of postoperative pain,

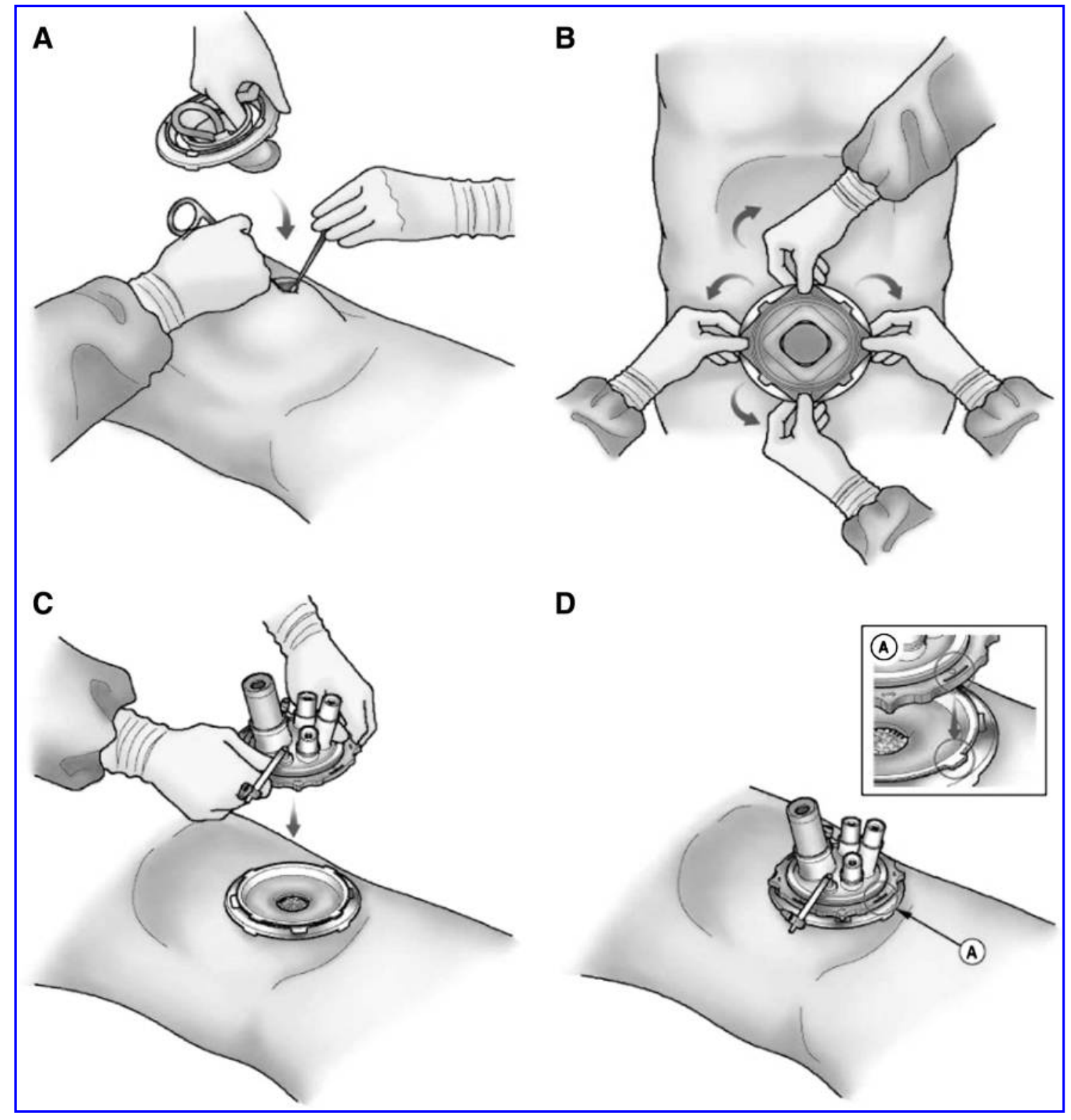

FIG. 3. Placement of Octoport system: (A) Insert the inferior base plate; (B) fix the external disc to the abdominal wall using the self-retractor; (C) put the silicone cover on the external disc; (D) fix the silicone cover to the external disc using the groove joint. 


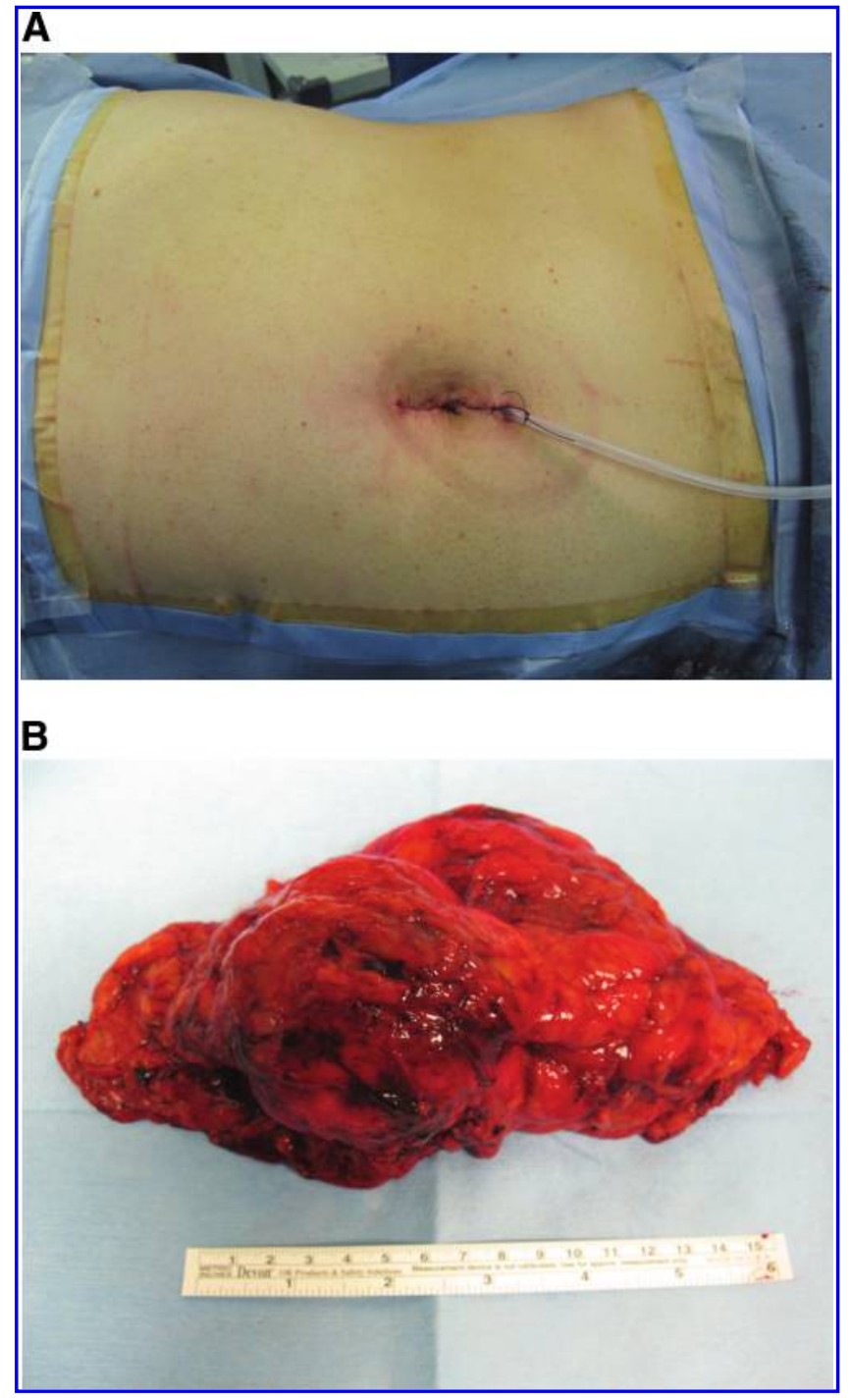

FIG. 4. Wound and surgical specimen: (A) Postoperative view of the wound; (B) surgical specimen.

postoperative hospital stay, and postoperative complications, as well as tumor characteristics between the two groups. Comparison of surgical and pathologic outcomes was performed by Mann-Whitney U-test for continuous variables and chi-square test for categorical variables. All $P$ values were two-sided, and data were considered statistically significant at $P<0.05$.

\section{Results}

\section{Patient demographics}

Patient characteristics are presented in Table 1. Of the 57 case-matched patients who were evaluated, 42 male and 15 female patients with a mean age of 51.2 years (22-78 yrs) were included in this study. Age, sex, body mass index, and American Society of Anesthesiologists score did not differ significantly between the groups. Patients from the LESS group underwent a higher number of previous abdominal surgeries compared with the conventional laparoscopy group ( $21.1 \%$ vs $10.5 \%, P=0.420)$, without statistical significance.
Table 1. Demographics for Patients Undergoing LESS AND CONVENTIONAL LAPAROSCOPIC RADicAl NePHRECTOMY

\begin{tabular}{lccc}
\hline & LESS & $\begin{array}{c}\text { Conventional } \\
\text { laparoscopy }\end{array}$ & P value \\
\hline No. of patients & 19 & 38 & - \\
Sex (\%) & & & 1.000 \\
$\quad$ Male & $14(73.7)$ & $28(73.7)$ & \\
$\quad$ Female & $5(26.3)$ & $10(26.3)$ & \\
Age (years) & $49.6(22-78)$ & $52.0(30-69)$ & 0.503 \\
BMI (kg/m $\left.{ }^{2}\right)$ & $25.4(21.1-34.7)$ & $24.2(18.8-27.7)$ & 0.165 \\
Previous abdominal & $4(21.1)$ & $4(10.5)$ & 0.420 \\
$\quad$ surgery (\%) & & & \\
ASA score (\%) & $11(57.9)$ & $21(55.3)$ & 0.332 \\
$\quad 1$ & $7(36.8)$ & $17(44.7)$ & \\
2 & $1(5.3)$ & $0(0)$ & \\
$\quad 3$ & & & \\
Operative side (\%) & $9(47.4)$ & $18(47.4)$ & \\
$\quad$ Right & $10(52.6)$ & $20(52.6)$ & \\
$\quad$ Left & &
\end{tabular}

LESS = laparoendoscopic single-site; $\mathrm{BMI}=$ body mass index; ASA $=$ American Society of Anesthesiologists.

\section{Surgical outcomes}

Table 2 shows surgical outcomes for patients who were undergoing LESS and conventional laparoscopic radical nephrectomy. There was no conversion in the LESS group and one conversion to open surgery in the conventional laparoscopy group. The reason for open conversion in the conventional laparoscopy group was noted as extensive bleeding from the inferior vena cava branch.

Although not significant, mean operative time was longer in the LESS group than in the conventional laparoscopy group (190.8 $\mathrm{min}$ vs $172.4 \mathrm{~min}, P=0.249$ ) and mean blood loss was lower in the LESS group than in the conventional laparoscopy group (143.2 $\mathrm{mL}$ vs $199.5 \mathrm{~mL}, P=0.235)$. Operative time, however, was decreased significantly as the number of patients increased (Spearman rho correlation coefficient $=-0.660, P=0.002$ ) (Fig. 5). There were no significant differences in transfusion rate and resumption of oral intake.

Mean postoperative pain, as measured by visual ana$\log$ scale at postoperative days 1 (4.7 vs 5.8 points, $P=0.001$ ), 2 (3.4 vs 4.6 points, $P<0.001$ ), and 3 (2.7 vs 4.0 points, $P=0.008)$ was significantly lower in the LESS group. Mean postoperative hospital stay after LESS radical nephrectomy was 2.7 days (2-4), compared with 3.9 days (3-7) after conventional laparoscopic radical nephrectomy $(P<0.001)$.

Perioperative complications were similar between the two groups. Complications included the following minor complications: Wound infection $(n=1)$, postoperative fever $(n=1)$ and postoperative urinary retention $(n=1)$ in the LESS group and postoperative fever $(n=2)$, postoperative urinary retention $(n=2)$, wound infection $(n=1)$, ileus $(n=1)$, drug eruption $(n=1)$, and chylous ascites $(n=1)$ in the conventional laparoscopy group. 
Table 2. Operative Characteristics for Patients UNDERGOING LESS AND CONVENTIONAL LAPAROSCOPIC RAdicAl NePHRECTOMY

\begin{tabular}{lccr}
\hline & LESS & $\begin{array}{c}\text { Conventional } \\
\text { laparoscopy }\end{array}$ & P value \\
\hline Conversion (\%) & $0(0)$ & $1(2.6)$ & 1.000 \\
$\begin{array}{l}\text { Operative time } \\
\text { (minutes) }\end{array}$ & 190.8 & $172.4(110-250)$ & 0.249 \\
$\begin{array}{l}\text { Estimated blood } \\
\text { loss (mL) }\end{array}$ & 143.2 & $199.5(50-500)$ & 0.235 \\
Transfusion (\%) & $(100-300)$ & & \\
Resumption of & $1.0(1-2)$ & $1.0(1-2)$ & 0.480 \\
$\quad$ oral intake (days) & & & \\
Analgesics & $39.5(0-100)$ & $45.4(0-125)$ & 0.577 \\
$\quad$ (mg of pethidine) & & & \\
Pain score & & & \\
$\quad$ Day 1 & $4.7(3-6)$ & $5.8(3-8)$ & 0.001 \\
$\quad$ Day 2 & $3.4(2-4)$ & $4.6(2-6)$ & $<0.001$ \\
$\quad$ Day 3 & $2.7(2-3)$ & $4.0(2-6)$ & 0.008 \\
Hospital stay (days) & $2.7(2-4)$ & $3.9(3-7)$ & $<0.001$ \\
Complications (\%) & $3(15.8)$ & $8(21.1)$ & 0.635 \\
\hline
\end{tabular}

LESS $=$ laparoendoscopic single-site.

\section{Pathologic outcomes}

Pathologic examination revealed RCC in all cases. Tumor size, pathologic $\mathrm{T}$ stage, histologic subtype, and Fuhrman nuclear grade were not significantly different in patients undergoing LESS radical nephrectomy compared with those undergoing conventional laparoscopic radical nephrectomy (Table 3). There was one patient with lymph node metastasis in the LESS group who had a $\mathrm{T}_{3 \mathrm{a}}$ clear cell RCC.

\section{Discussion}

Laparoscopic radical nephrectomy is now accepted as the gold standard for treatment of localized RCC. ${ }^{2-5}$ What was anecdotal in $1991^{1}$ has now evolved into a well-described, easily reproducible technique. Traditionally, laparoscopic radical nephrectomy has been performed with four or five ports, most commonly two $12-\mathrm{mm}$ ports and two or three $5-\mathrm{mm}$ ports. The trend has been toward minimizing the number of incisions and ports, leading to the introduction of LESS radical nephrectomy.

To date, however, the experience with LESS radical nephrectomy for RCC has been reported in descriptive studies. ${ }^{10,13,14}$ Stolzenburg and associates ${ }^{13}$ reported their technique and experience with 10 LESS radical nephrectomies; the mean operative time was 146.4 minutes and blood loss was $202 \mathrm{~mL}$. To our knowledge, this descriptive study included the largest number of patients who received LESS radical nephrectomy to date. The study, however, did not show evidence-based clinical trial data on this technique because of the descriptive nature of their study.

A comparative series between conventional laparoscopic nephrectomy has been performed in only two studies. ${ }^{15,16}$ Results from these studies demonstrated no difference in mean operative time, analgesic use, postoperative hospital stay, and complication rate between the two approaches. An important limitation of their studies, however, was inclusion of patients with nonfunctioning kidney, as well as those with RCC, which obscures the possible benefits of LESS nephrectomy by including two different disease entities.

Results from the current study demonstrated significantly less postoperative pain and shorter hospital stay in the LESS group. These findings are not consistent with previous studies. We believe, however, that our study has an advantage over previous studies because of the homogeneity of the study population. Other factors that may play an important role in the postoperative pain of patients who underwent laparoscopic surgery were identical, except for the number and size of the incision in both groups. It is unlikely that the decreased postoperative pain score after LESS radical nephrectomy was an artifact of bias.

The distinctive feature of our study was that we attempted to analyze the learning curve for LESS radical

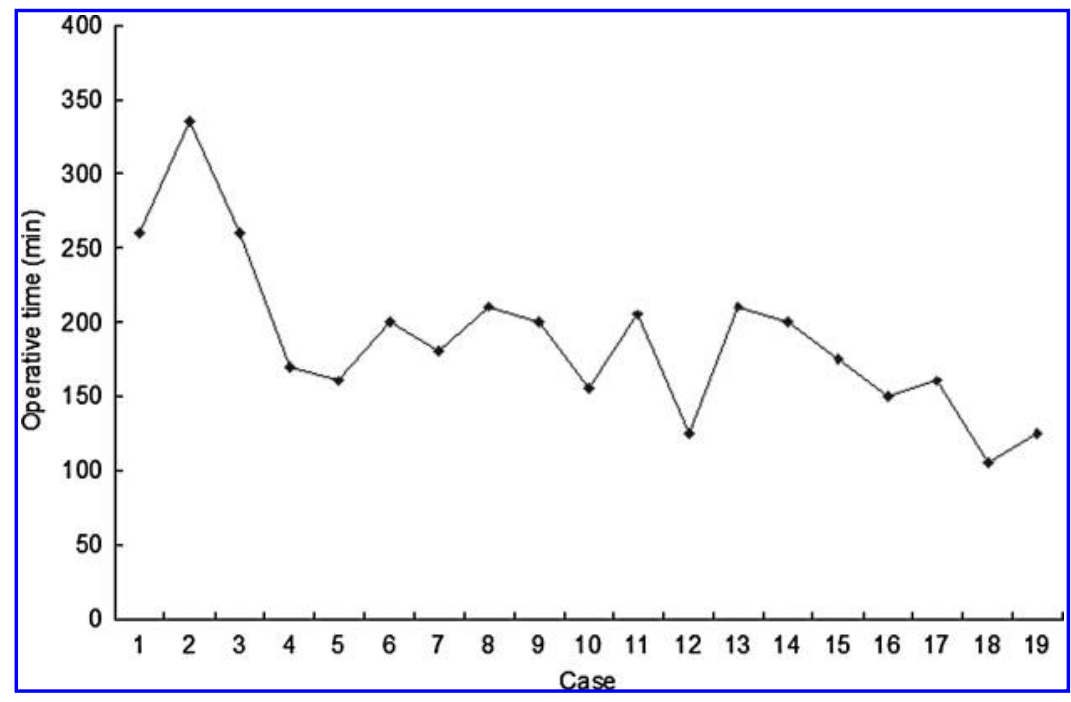

FIG. 5. Learning curve for operative time in LESS radical nephrectomy (Spearman rho correlation coefficient $=-0.660$, $P=0.002)$. 
Table 3. Pathologic Characteristics for Patients Undergoing Less and CONVENTIONAL LAPAROSCOPIC RAdicAl NePHRECTOMY

\begin{tabular}{lccc}
\hline & LESS & $\begin{array}{c}\text { Conventional } \\
\text { laparoscopy }\end{array}$ & P value \\
\hline Tumor size (cm) & $4.3(2-8)$ & $4.1(1.3-9)$ & 0.553 \\
T stage (\%) & $17(89.5)$ & $34(89.5)$ & 1.000 \\
$\mathrm{~T}_{1}$ & $1(5.3)$ & $2(5.3)$ & \\
$\mathrm{T}_{2}$ & $1(5.3)$ & $2(5.3)$ & \\
$\mathrm{T}_{3}$ & & & 0.333 \\
$\mathrm{~N} \mathrm{stage} \mathrm{( \% )}_{\mathrm{N}_{0}}$ & $18(94.7)$ & $38(100)$ & \\
$\mathrm{N}_{1}$ & $0(0)$ & $0(0)$ & \\
$\mathrm{N}_{2}$ & $1(5.3)$ & $0(0)$ & \\
Histologic subtype (\%) & & & 0.114 \\
Clear cell type & $13(68.4)$ & $35(92.1)$ & \\
Chromophobe type & $3(15.8)$ & $2(5.3)$ & \\
Papillary type & $2(10.5)$ & $1(2.6)$ & \\
Unclassified type & $1(5.3)$ & $0(0)$ & \\
Fuhrman nuclear grade (\%) & & & 0.345 \\
1 & $0(0)$ & $3(7.9)$ & \\
2 & $10(52.6)$ & $22(57.9)$ & \\
3 & $9(47.4)$ & $13(34.2)$ & \\
\hline
\end{tabular}

LESS $=$ laparoendoscopic single-site.

nephrectomy in its early stage. LESS is a technically demanding procedure that requires a high degree of spatial resolution, dexterity, and technical skill. Assessment of operator competency is an important aspect of quality assurance in patient care. Although the number of patients was small, operative time reduced with experience and reached statistical significance within the initial 13 cases, showing the effect of the learning curve. We can speculate that a short learning curve for this procedure stands on the basis of extensive previous laparoscopic experience with socalled advanced laparoscopic surgery and training for LESS in a porcine model.

We have used the Octoport to perform two LESS radical nephrectomies. This device has several distinctive advantages over the previous single-port device. The Octoport was inserted into the peritoneal cavity after incision of the skin, fascia, and peritoneum, which may serve to avoid intraabdominal vascular and visceral injury and abdominal wall bleeding. The tamponade effect of the self-retractor of the external disc may also contribute to decreased risk of subcutaneous emphysema, as well as port-site bleeding. Finally, the cover of the Octoport is constructed of semitransparent silicone, through which we can look into the peritoneal cavity to a certain extent to reduce the risk of peritoneal entry of the sharp laparoscopic instrument.

The potential limitations of this study should be considered. The major limitation was the nonrandomized and retrospective nature of the study design, susceptible to all limitations and biases that are inherent in a retrospective design. We tried to control, however, many factors that could influence the results in our analysis; therefore, despite the limitations of the study, LESS radical nephrectomy is certainly comparable or preferable to conventional laparoscopic radical nephrectomy with regard to subjective cosmetic results and objective surgical results.
Another potential limitation is that there were only a small number of reported cases. We believe, however, that a study to assess whether or not outcomes of LESS radical nephrectomy are comparable or superior to those obtained with a conventional laparoscopic approach would be of particular interest, because no comparative studies have been conducted to compare LESS and conventional laparoscopic radical nephrectomy.

\section{Conclusions}

Although technically demanding, LESS radical nephrectomy is safe and effective, resulting in less postoperative pain and shorter postoperative hospital stay compared with conventional laparoscopic radical nephrectomy.

\section{Disclosure Statement}

No competing financial interests exist.

\section{References}

1. Clayman RV, Kavoussi LR, Soper NJ, et al. Laparoscopic nephrectomy: Initial case report. J Urol 1991;146:278282.

2. Colombo JR Jr, Haber GP, Aron M, et al. Oncological outcomes of laparoscopic radical nephrectomy for renal cancer. Clinics (Sao Paolo) 2007;62:251-256.

3. Hemal AK, Kumar A, Kumar R, et al. Laparoscopic versus open radical nephrectomy for large renal tumors: A long-term prospective comparison. J Urol 2007;177:862866.

4. Kawauchi A, Yoneda K, Fujito A, et al. Oncologic outcome of hand-assisted laparoscopic radical nephrectomy. Urology 2007;69:53-56.

5. Bandi G, Christian MW, Hedican SP, et al. Oncological outcomes of hand-assisted laparoscopic radical nephrectomy for clinically localized renal cell carcinoma: A singleinstitution study with $>$ or $=3$ years of follow-up. BJU Int 2008;101:459-462.

6. Delgado S, Ibarzábal A, Fernández-Esparrach G. [Natural orifice transluminal endoscopic surgery: Current situation]. (Spa) Gastroenterol Hepatol 2008;31:515-521.

7. Desai MM, Berger AK, Brandina R, et al. Laparoendoscopic single-site surgery: Initial hundred patients. Urology 2009; 74:805-812.

8. Canes D, Desai MM, Aron M, et al. Transumbilical singleport surgery: Evolution and current status. Eur Urol 2008;54: 1020-1029.

9. Kommu SS, Kaouk JH, Rané A. Laparo-endoscopic singlesite surgery: Preliminary advances in renal surgery. BJU Int 2009;103:1034-1037.

10. Stolzenburg JU, Hellawell G, Kallidonis P, et al. Laparoendoscopic single-site surgery: Early experience with tumor nephrectomy. J Endourol 2009;23:1287-1292.

11. Kavoussi LR, Kerbl K, Capelouto CC, et al. Laparoscopic nephrectomy for renal neoplasms. Urology 1993;42: 603-609.

12. Park YH, Kang MY, Jeong MS, et al. Laparoendoscopic single-site nephrectomy using a homemade single-port device for single-system ectopic ureter in a child: Initial case report. J Endourol 2009;23:833-835.

13. Stolzenburg JU, Kallidonis P, Hellawell G, et al. Technique of laparoscopic-endoscopic single-site surgery radical nephrectomy. Eur Urol 2009;56:644-650. 
14. Raman JD, Bensalah K, Bagrodia A, et al. Laboratory and clinical development of single keyhole umbilical nephrectomy. Urology 2007;70:1039-1042.

15. Raman JD, Bagrodia A, Cadeddu JA. Single-incision, umbilical laparoscopic versus conventional laparoscopic nephrectomy: A comparison of perioperative outcomes and short-term measures of convalescence. Eur Urol 2009;55: 1198-1204.

16. Raybourn JH III, Rane A, Sundaram CP. Laparoendoscopic single-site surgery for nephrectomy as a feasible alternative to traditional laparoscopy. Urology 2009; Jul 21. Epub ahead of print.
Address correspondence to: Hyeon Hoe Kim, M.D., Ph.D. Department of Urology Seoul National University Hospital

28 Yeongeon-dong, Jongno-gu Seoul 110-744 Korea

E-mail: hhkim@snu.ac.kr

\section{Abbreviations Used}

LESS = laparoendoscopic single-site

NOTES $=$ natural orifice translumenal endoscopic surgery $\mathrm{RCC}=$ renal-cell carcinoma 



\section{This article has been cited by:}

1. Takatsugu Okegawa, Naoshi Itaya, Hidehiko Hara, Kikuo Nutahara, Eiji Higashihara. 2012. Initial operative experience of single-port retroperitoneal laparoscopic nephrectomy. International Journal of Urology no-no. [CrossRef]

2. Yong Hyun Park, Kyung Don Baik, Young Ju Lee, Kwang Taek Kim, Hyeon Hoe Kim . 2012. Learning Curve Analysis for Laparoendoscopic Single-Site Radical Nephrectomy. Journal of Endourology 26:5, 494-498. [Abstract] [Full Text HTML] [Full Text PDF] [Full Text PDF with Links]

3. Aditya Bagrodia, Jeffrey A. Cadeddu. 2012. Surgery: Are we likely to see more of LESS in urological surgery?. Nature Reviews Urology . [CrossRef]

4. Sara L. Best, Richard Bergs, Daniel J. Scott, Raul Fernandez, Lauren B. Mashaud, Jeffrey A. Cadeddu . 2012. Solo Surgeon Laparo-Endoscopic Single Site Nephrectomy Facilitated by New Generation Magnetically Anchored and Guided Systems Camera. Journal of Endourology 26:3, 214-218. [Abstract] [Full Text HTML] [Full Text PDF] [Full Text PDF with Links]

5. Ithaar H. Derweesh. 2012. Whither the Long March of LESS. The Journal of Urology . [CrossRef]

6. Ji Sun Kim, Seung-Yong Jeong, Ra-Yeong Song, Heung-Kwon Oh, Rumi Shin, Yong Hyun Park, Hyeon Hoe Kim . 2012. Single-Incision Laparoscopic Anterior Resection with Simultaneous Radical Nephrectomy. Journal of Laparoendoscopic and Advanced Surgical Techniques, Part B: Videoscopy 22:1. . [Abstract] [Full Text HTML]

7. Ephrem O. Olweny, Saad A. Mir, Sara L. Best, Samuel K. Park, Chester Donnally III, Jeffrey A. Cadeddu, Chad R. Tracy. 2012. Importance of cosmesis to patients undergoing renal surgery: a comparison of laparoendoscopic single-site (LESS), laparoscopic and open surgery. BJU International no-no. [CrossRef]

8. Linhui Wang, Bing Liu, Zhenjie Wu, Qing Yang, Wei Chen, Zunli Xu, Cheng Wang, Liang Xiao, Fubo Wang, Yinghao Sun . A Matched-Pair Comparison of Laparoendoscopic Single-Site Surgery and Standard Laparoscopic Radical Nephrectomy by a Single Urologist. Journal of Endourology, ahead of print. [Abstract] [Full Text HTML] [Full Text PDF] [Full Text PDF with Links]

9. Jens-Uwe Stolzenburg, Panagiotis Kallidonis, Narasimhan Ragavan, Anja Dietel, Minh Do, Phuc Ho Thi, Holger Till, Evangelos N. Liatsikos. 2011. Clinical outcomes of laparo-endoscopic single-site surgery radical nephrectomy. World Journal of Urology . [CrossRef]

10. Francesco Greco, Luca Cindolo, Riccardo Autorino, Salvatore Micali, Robert J. Stein, Giampaolo Bianchi, Caterina Fanizza, Luigi Schips, Paolo Fornara, Jihad Kaouk. 2011. Laparoendoscopic Single-Site Upper Urinary Tract Surgery: Assessment of Postoperative Complications and Analysis of Risk Factors. European Urology . [CrossRef]

11. Jeffrey M. Woldrich, Nicholas Holmes, Kerrin Palazzi-Churas, Madhu Alagiri, Marvalyn DeCambre, George Kaplan, George Chiang. 2011. Comparison of Laparoendoscopic Single-Site, Conventional Laparoscopic, and Open Nephrectomy in a Pediatric Population. Urology 78:1, 74-77. [CrossRef]

12. Nelson Salas, Michael A. Gorin, Vladislav Gorbatiy, Scott M. Castle, Vincent G. Bird, Raymond J. Leveillee . 2011. Laparoendoscopic Single Site Nephrectomy With the SPIDER Surgical System: Engineering Advancements Tested in a Porcine Model. Journal of Endourology 25:5, 739-742. [Abstract] [Full Text HTML] [Full Text PDF] [Full Text PDF with Links]

13. Harveer Dev, Prasanna Sooriakumaran, Ashutosh Tewari, Abhay Rane. 2011. LESSons in minimally invasive urology. BJU International 107:10, 1555-1559. [CrossRef]

14. Michael A. White, Riccardo Autorino, Gregory Spana, Humberto Laydner, Shahab P. Hillyer, Rakesh Khanna, Bo Yang, Fatih Altunrende, Wahib Isac, Robert J. Stein, Georges-Pascal Haber, Jihad H. Kaouk. 2011. Robotic Laparoendoscopic SingleSite Radical Nephrectomy: Surgical Technique and Comparative Outcomes. European Urology 59:5, 815-822. [CrossRef]

15. Udo Nagele, Ute Walcher, Thomas R. W. Herrmann. 2011. Initial experience with laparoscopic single-incision triangulated umbilical surgery (SITUS) in simple and radical nephrectomy. World Journal of Urology . [CrossRef]

16. Chang Wook Jeong, Eun Tak Kim, Hyeon Jeong, Yong Hyun Park, Chang Ju Lee, Hahn-Ey Lee, Hyeon Hoe Kim, Seung Bae Lee . 2011. Laparoendoscopic Single-Site Pyeloplasty with Concomitant Pyelolithotomy Using Flexible Cystoscope. Journal of Endourology Part B, Videourology 25:2. . [Abstract] [Full Text HTML]

17. Sara L. Best, Chester Donnally, Saad A. Mir, Chad R. Tracy, Jay D. Raman, Jeffrey A. Cadeddu. 2011. Complications during the initial experience with laparoendoscopic single-site pyeloplasty. BJU International no-no. [CrossRef]

18. Jae Duck Choi, Hong Seok Kim, Sung Ho Ju, Seo Yeon Lee, Deok Hyun Han, Byong Chang Jeong. 2011. Initial experience with LESS and hybrid LESS in patients with benign urologic disease. Minimally Invasive Therapy \& Allied Technologies 1-8. [CrossRef] 
19. Nina Casanova , J. Stuart Wolf , Jr. . 2011. The Alternative to Laparoendoscopic Single-Site Surgery: Small Strategic Laparoscopic Incision Placement (SLIP) Nephrectomy Improves Cosmesis Without Technical Restrictions. Journal of Endourology 25:2, 265-270. [Abstract] [Full Text HTML] [Full Text PDF] [Full Text PDF with Links]

20. Masaru Ishida, Akira Miyajima, Toshikazu Takeda, Masanori Hasegawa, Eiji Kikuchi, Mototsugu Oya. 2010. Technical difficulties of transumbilical laparoendoscopic single-site adrenalectomy: comparison with conventional laparoscopic adrenalectomy. World Journal of Urology . [CrossRef]

21. Harveer S. Dev, Prasanna Sooriakumaran, Ashutosh K. Tewari. 2010. Single-Site Surgery: More oR-LESS?. European Urology 58:6, 849-850. [CrossRef]

22. Rakesh Khanna, Humberto K Laydner, Wahib Isac, Robert J Stein. 2010. Laparoendoscopic single-site surgery for renal malignancies. Expert Review of Anticancer Therapy 10:12, 1861-1863. [CrossRef]

23. Michael A. White, Georges-Pascal Haber, Riccardo Autorino, Rakesh Khanna, Sylvain Forest, Bo Yang, Fatih Altunrende, Robert J. Stein, Jihad H. Kaouk. 2010. Robotic Laparoendoscopic Single-Site Radical Prostatectomy: Technique and Early Outcomes. European Urology 58:4, 544-550. [CrossRef] 